\title{
Comparative Analysis of Different Designs of Triple Tube Heat Exchangers on the Basis of their Performances
}

\author{
Vivek Kumar Gautam \\ M.Tech Scholar \\ Department of Mechanical Engineering \\ Sagar Institute of Research \& Technology \\ Bhopal, M.P, India \\ vk.gautam0492@gmail.com
}

\author{
Prof. NK Sagar \\ Assistant Professor \\ Department of Mechanical Engineering \\ Sagar Institute of Research \& Technology \\ Bhopal, M.P, India
}

\begin{abstract}
Cooling, warming, and air-conditioning systems, electric utilities, chemical based processing structures, food industry, automotive vehicle radiators, and waste heat recovery units are all examples of heat exchanger implementations. Heat exchangers in power plants include air preliminary heaters, economizers, evaporators, superheaters, condensing systems, and cooling towers. Theoretical and simulation fluid dynamics assessments of varying patterns of a concentric TTHEX were conducted in this study with the intent of enhancing thermal efficiency.
\end{abstract}

Keyword $s$ : Heat exchanger, Shell and Tube Heat Exchanger, Triple tube Heat Exchangers.

\section{INTRODUCTION}

A heat exchanger is an equipment that transfers heat from one fluid to another. The fluids could be single-phase or dualphase, and they can be detached or in straight contact, relying on the type of exchanging device. Although most of the underlying facts in their architecture are similar, equipment incorporating renewable resources including nuclear fuel pins or fired heating systems are not commonly considered as heat exchanging device. A heat exchanger is a device that allows heat to be transferred among multiple fluids with varying temperatures. Cooling, heating, and air-conditioning systems, power plants, chemical manufacturing devices, food industry mechanisms, automotive vehicle radiators, and waste heat recovery units are all examples of heat exchanger implementations.Heat exchanging system in power plants include air preliminary heaters, economizers, evaporator coils, super-heaters, condensing system, and cooling systems.

Heat exchanging devices are commonly found on classical oil and gas or bulk chemical process plants, although they are less prevalent in many other sectors like food and medical products. The shell and tube heat exchanger is the current conventional kind of heat exchanger, although there are several variations of this configuration as well as several other different kinds of heat exchangers that are better suited for this purpose including such hygienic duty. In the pharmacological, core competency, agribusiness, fine chemical, groceries, and beverage businesses, batch secondary heat transferring cycles are particularly prevalent.

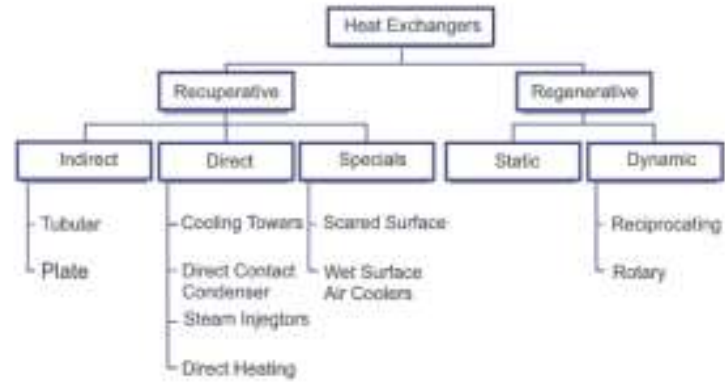

Figure 1 On the basis of Classification of Heat exchanges Construction

\section{LITERATURE REVIEW}

(Moya-Rico et al., 2019)[1]The Artificial Neural Network strategy is employed in this document to forecast the heat transfer characteristics and pressure fall in a triple concentrictube heat exchanging device with corrugated and noncorrugated internal tubes and conventional food manufacturing fluids. Due to the obvious inherent characteristics of the Artificial Neural Network technique, that also conventional studies with basic correlations dearth, it can forecast observational evidence with mistakes on par with the errors in measurement. Although when precisely defined relevant factors are implicated, including in heat exchanger configuration, the neural network's ability to comprehend trends enables it to encapsulate all of the complicated physics excluding the requirement for mathematical equations.In theory, these characteristics that make the Artificial Neural Network strategy appropriate for estimating the heat transferring rate and pressure fall in various conditions.

(Bahiraei, Mazaheri, et al., 2019)[2] In a triple-tube heat exchanging devices including inserted ribs, the existing article tries to mathematically investigate the hydro-thermal attributes and energy achievement of a hybrid nano-fluid comprising graphene nanoplatelet-platinum reinforced powder. Ice chilled water and normalized water circulate in 
the tube side and exterior annulus side, including both, while nano-fluid circulates in the internal annulus. The ribs are attached to the internal tube's exterior surface. By raising the nano-particle intensity and rib height while lessening the rib pitch, the heat exchanger device complete heat transferring coefficient, performance, and heat transferring rate are improved.

(Said et al., 2019)[3] The optimization of Shell-and-Tube Heat Exchanging device has always been a key objective for designing professionals in industrial operations. This research examined into enhancing energy effectiveness of heat exchangers while keeping the complete expense and energy usage low. The stabilization, thermo-physical characteristics, heat transfer effectiveness, and potential minimization of the effective area of a Shell-and-Tube Heat Exchanging device using $\mathrm{CuO} /$ water nanofluid are all explored. The concentrations of nanoparticles employed were $0.05,0.1$, and 0.3 vol percent. Addinally to the experimental study, a conceptual theory was established to validate the findings. For the similar fluid injector temperatures and mass circulation rates, the convective heat transferring coefficient acquired in the scenario of operating condition with nanofluid is marginally greater than the base fluid.

(Karimi et al., 2019) [4] The simulating results of nanofluid circulation in a dual tube heat exchanging device including twisted tape was the subject of this research. Operating fluids involve an alumina or water nanofluid and pure water. For nanofluid circulate simulation, a dual-phase mixture model was employed. The impact of nanofluid as well as twisted tape on the heat exchanging device hydrodynamic and thermal efficiency was investigated. The impact of twisted tape area roughness (material type) on heat exchange and pressure fall in the heat exchanging device was then studied. For different Reynolds numbers, nanofluid densities, pitch ratios, and tape inset substance, the findings are reported as temperature distribution, velocity field, Nusselt number, and pressure falls.

Mahdi et al., 2019)[5] This research looked into the TTHX's concurrently charging process and discharging process. Simplified longitudinal fins were adhere to the external tube carrying the low temperature HTF to offer rapid reaction for thermal energy restoration from the storage container, whereas a fin framework having a flexible setup was connected to the internal tube tube comprised of the hot HTF to expedite the energy storage processing and increamentin the final liquid fraction. The findings show that the geometrical factors of the fin structure discovered in the investigation have a serious influence on the collection unit's thermal response. Also it was discovered that even the most efficacious criterion for assessing the results of the thermal storage unit under SCD circumstances is achieving final steady liquid fraction.

(Bahiraei, Kiani Salmi, et al., 2019)[6] The thermal and hydraulic properties of an ecologically responsible graphene nanofluid circulating through a counter-current spiral heat exchanging devices are investigated in the present study. The low temperature water circulates on either side of the heat exchanging device, whereas the high temperature nanofluid or high temperature base fluid circulates on the other. Having increased Reynolds number or density, the heat transferring rate and complete heat transfer coefficient improve. At higher Reynolds numbers, the influence of ssurplus nanoparticles is becoming more significant. The highest heat exchange occurs in the heat exchanging device end sections at high Reynolds numbers, whereas the primary heat transfer occurs in the heat exchanger's initial sections at low Reynolds numbers. The findings demonstrate that the value of efficiency is very much higher (greater than 0.85) in all of the situations studied. Moreover, the effectiveness and number of transfer units decrease by increasing the Reynolds number.

\section{METHODOLOGY}

The refrigeration behaviour of the shell-and-tube exchanging device is achieved by circulating a high temperature liquid through tubes that consist of a low temperature liquid. In the shell, which is really a protected area, the high temperature liquid spreads. The low temperature liquid is transported thru the shell in tubes that also are coiled. Whereas the low temperature liquid in the tubes warms up the higher temperature liquid in the shell, the warmer liquid in the shell begins to loose the heat the relatively low temperature liquid within the tubes.

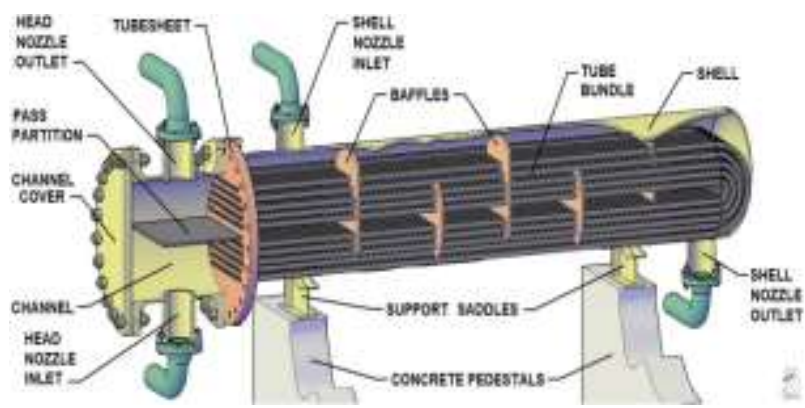

Figure 2 Elements of Shell and Tube Heat Exchanger

A parametric study of a concentric triple tube heat exchanger for lowering the temperature was widely carried out in the present investigation. $\mathrm{T}(\mathrm{cf} 1$ (in)) in the internal tube and $\mathrm{T}$ (cf1(out)) in the external tube, respectively, and $\mathrm{T}(\mathrm{cf} 2$ (in)) in the internal tube and $\mathrm{T}$ ( $\mathrm{cf} 2$ (out)) in the external tube. The high temperature fluid to be cooled enters the TTHEX (triple tube heat exchanger) at a temperature of $\mathrm{T}$ (hf1(in)) and exits at a temperature of $\mathrm{T}$ (c1(in)) from the intrinsic annular space.

Whenever the high temperature fluid circulates in the same manner as the low temperature fluid and when the high temperature fluid circulates in the opposite direction of the cold fluid, the heat transfer architecture in a TTHEX differs. As a result, the equations for these two structures are investigated separately.

The physicochemical characteristics of the fluid, as well as its velocity, influence the heat transfer coefficient. The heat 
transferring coefficient is a feature of the fluid concentration that responds to fluctuations in the thermal and physical properties of the liquid, as well as the rigidity to molecular diffusion in the fluid closer to the bubble.

$$
U=\frac{Q_{h}}{I_{A} \times L_{\text {avg }}}
$$

The Nusselt number is the ratio of convection to conduction heat transferring across a boundary $(\mathrm{Nu})$. The convective heat and condensation heat circulations are, in broad sense, perpendicular to the surface to the average fluid circulation and parallel to the plane normal of the boundary plane.

$$
N u_{n f}=\frac{H_{n f} D_{h f, n f}}{K_{n f}}=\frac{23}{1000} \times R_{e, n f}^{0.8} \times P r_{n f}^{0.4}
$$

\begin{tabular}{|c|l|l|l|l|}
\hline $\begin{array}{c}\boldsymbol{\varphi} \\
(\boldsymbol{\%})\end{array}$ & $\begin{array}{c}\text { Density } \\
\left(\mathbf{k g} / \mathbf{m}^{\mathbf{3}}\right)\end{array}$ & $\begin{array}{c}\text { Specific } \\
\text { heat } \\
(\mathbf{J} / \mathbf{k g K})\end{array}$ & \multicolumn{1}{|c|}{$\begin{array}{c}\text { Viscosity } \\
(\mathbf{k g} / \mathbf{m s})\end{array}$} & $\begin{array}{c}\text { Thermal } \\
\text { conductivit } \\
\mathbf{y}(\mathbf{W} / \mathbf{m K}) \\
\mathbf{x 1 0}\end{array}$ \\
\hline 0 & $1086.05-$ & $0.12 \mathrm{~T}+$ & 3082123033 & $0.002029 \mathrm{~T}-$ \\
& $0.2978 \mathrm{~T}$ & 4065.8 & $04492.30 \times T$ & 0.0056 \\
\hline 0.02 & 1085.5 & $4250.2-$ & 1375730786 & $0.002505 \mathrm{~T}-$ \\
& $0.4 \mathrm{~T}$ & $0.72569 \mathrm{~T}$ & $076.29 \times T^{-6.10}$ & 0.1678 \\
& & & 768 & \\
\hline 0.06 & $1084.1-$ & 4247.1 & 70454606.65 & $0.0028 \mathrm{~T}-$ \\
& $0.2932 \mathrm{~T}$ & $0.7661 \mathrm{~T}$ & $\times T^{-4.366}$ & 0.2325 \\
\hline 0.1 & $1085.4-$ & $1.01 \mathrm{~T}+$ & 351860109.2 & $0.0030 \mathrm{~T}-$ \\
& $0.2968 \mathrm{~T}$ & 3382.5 & $6 \times T^{-4.63845}$ & 0.2545 \\
\hline
\end{tabular}

Com putat ion of Nuss elt no. of cold wate r:

$$
\begin{gathered}
N u_{\text {cold }}=\frac{H_{\text {cold }} D_{h f, \text { cold }}}{K_{\text {cold }}} \\
\quad=\frac{23}{1000} \times R_{e, \text { cold }}^{0.8} \times \operatorname{Pr}_{\text {cold }}{ }^{0.4}
\end{gathered}
$$

Computation of Nusselt no. of normalized water:

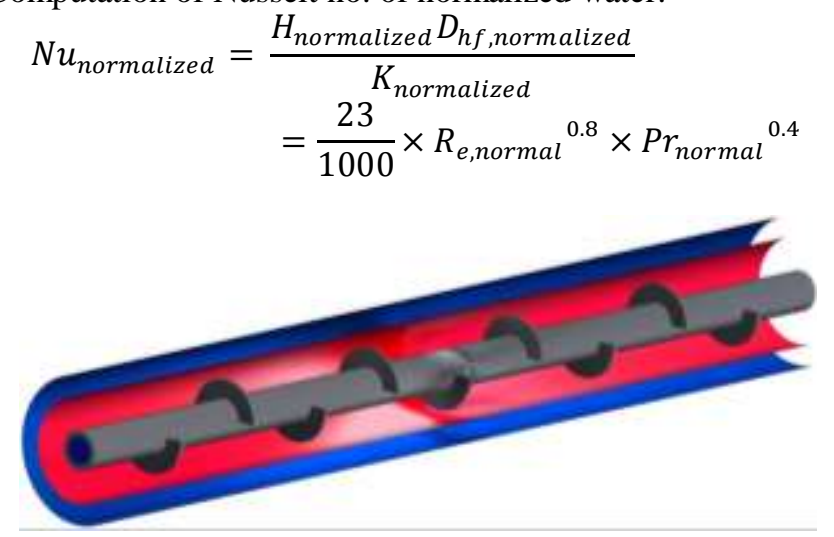

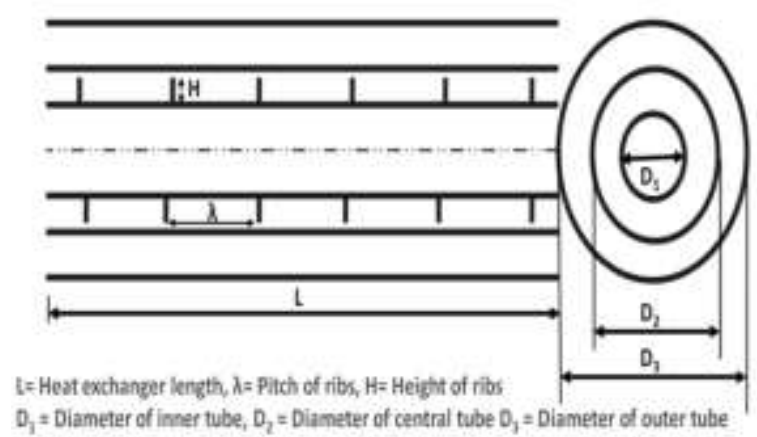

Figure 3Concentric TTHEX concept based schematic

In this research, a three-dimensional Computer Aided Design modelling of a concentric TTHEX (triple tube heat exchanger) with Linear baffle is invented employing the architectural style fully programmable of the ANSYS software. Internal tubes have a radius of $6.76 \mathrm{~mm}$, middle tubes have a radius of $22.68 \mathrm{~mm}$, and external tubes have a radius of $35.28 \mathrm{~mm}$ and a length of $500 \mathrm{~mm}$, as shown in Figure 4.

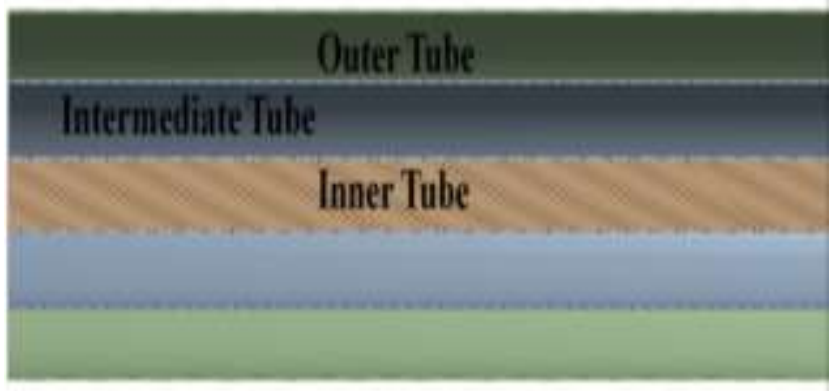

Figure 4Modeling using computer-aided design for concentric TTHEX excluding baffles

\section{Graphene nano-platelets-platinum nano - fluids thermo -} physical characteristics

The temperature of the graphene nanoplatelets-platinum nano - fluid at the internal tube's opening is assumed to be 343 Kelvin. At 0.1 percent weight fragments, characteristics of graphene nano-platelets-platinum nano-fluid.

\begin{tabular}{|c|c|c|c|c|}
\hline $\begin{array}{c}\text { Density } \\
\left(\mathbf{k g} / \mathbf{m}^{\mathbf{3}}\right)\end{array}$ & $\begin{array}{c}\text { Specific } \\
\text { heat } \\
(\mathbf{J} / \mathbf{k g K})\end{array}$ & $\begin{array}{c}\text { Viscosity } \\
(\mathbf{k g} / \mathbf{m s})\end{array}$ & $\begin{array}{c}\text { Thermal } \\
\text { conductivity } \\
(\mathbf{W} / \mathbf{m K}) \mathbf{x 1 0} \mathbf{3}^{\mathbf{3}}\end{array}$ & $\begin{array}{c}\text { Prandtl } \\
\text { Number } \\
\mathbf{P}_{\mathbf{r}}=\frac{\boldsymbol{\mu} \cdot \mathbf{c}_{\mathbf{p}}}{\mathbf{k}}\end{array}$ \\
\hline 984.3102 & 3731.36 & $\begin{array}{c}0.000611 \\
78\end{array}$ & 0.822 & 2.8134 \\
& & & \\
\hline
\end{tabular}

\section{RESULT AND DISCUSSION}

For the purpose of improving thermal performance, analytical and numerical fluid dynamics assessments of various styles of a concentric TTHEX were implemented in this research. Straight and slanted baffles with tilt angles of $30^{\circ}$ and $45^{\circ}$ were utilised for the internal tube of a concentrated TTHEX. The concentric TTHEX is categorized into three sectors for this assessment, including two low temperature fluid realms 
and one greater temperature fluid in the middle tube, as well as low temperature fluid in the internal and external tubes.

In the computational sectors, fluent software is used to determine fluid circulation and heat transfer. The governing equations are iterative manner solved using the SIMPLE methodology and the finite elements conceptualization. Since the swirling impact on turbulence circulation has greater accuracy than the standard k-epsilon concept, the RNG kepsilon model will be used for turbulence circulation, and the 2nd order incentive scheme will be utilised for momentum energy turbulence and its thermal diffusivity

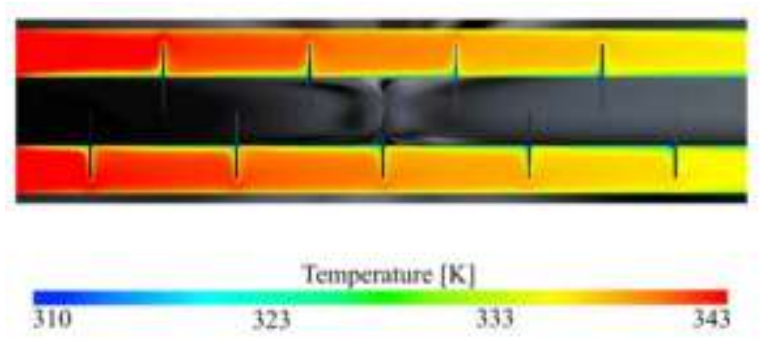

(a) NimaMazaheri et al (2019)

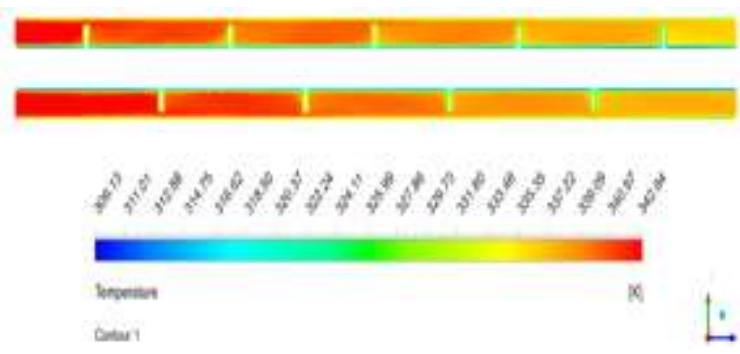

(b) Proposed work

As seen in the following table, the percentage variability assessment of NimaMazaheri et al. and the recent research with contour schematic and temperature distribution across tube length demonstrate very little variability tend to range from 0.04 percent for highest to 0.28 percent for lowest value of temperature

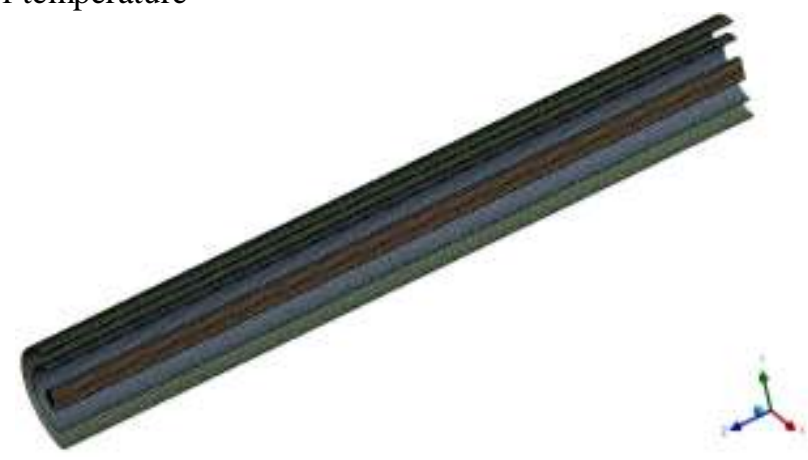

Figure 5 Linear baffles meshing in concentric TTHEX

In CFD assessment, meshing is a special task in which Computer aided geometry is categorised into a group of small segments popularly known as mesh. As can be seen in figure 5 , the overall number of nodes engendered in this work is 3918316 , and the total number of elements is 3059514 . The element types produced in this meshing are tet 4 , Hex8, and Wed6, with a $0.5 \mathrm{~mm}$ component dimension.

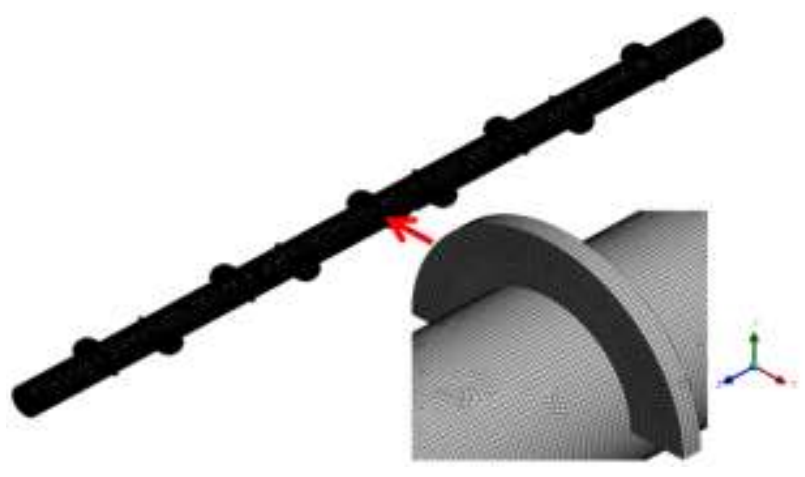

Figure 6 Straight baffles mesh in concentric TTHEX

In CFD assessment, meshing is a special task in which Computer aided geometry is segmented into a group of small sections which can be defined as mesh. As seen in the figure 4.9 , the overall quantity of nodes obtained in this research is 984143 , and the overall number of elements is 1000209 . This meshing generates tet 4 , Hex 8 , and Wed6 elements with a 0.5 mm element dimensioning.

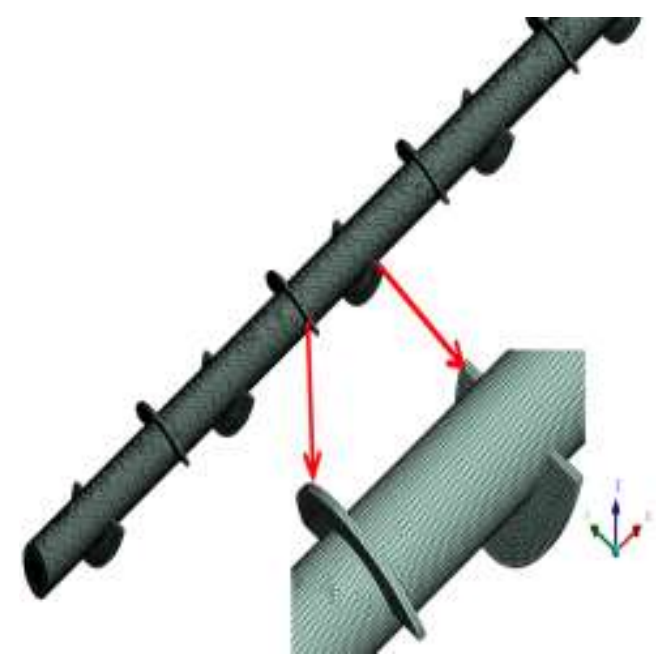

Figure 7 At 30 degrees, a concentric TTHEX with sloped baffles is mesh generation

As seen in figure 7 , the overall number of nodes obtained in this work is 2243582, and the overall number of attributes yielded is 6580483 . The component varieties yielded in this meshing are tet 4 , Hex 8 , and Wed6, having a $0.5 \mathrm{~mm}$ element dimensioning. 


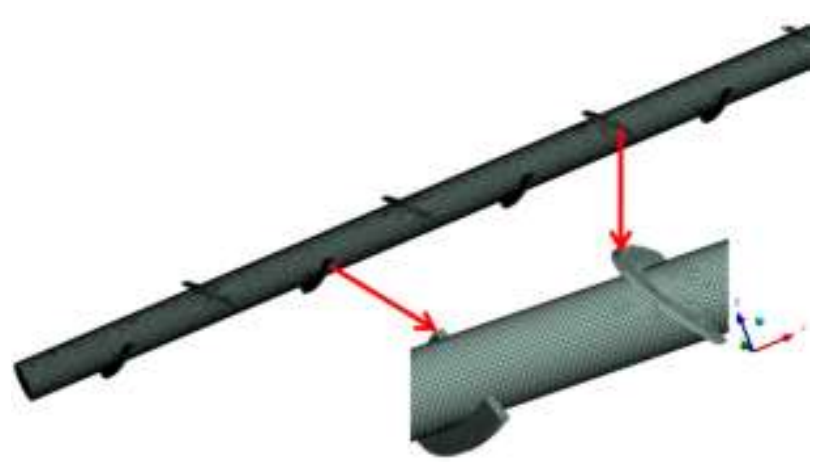

Figure 8 At 45 degrees, a concentric TTHEX with sloped baffles is meshed

As can be seen in figure 8 , the overall quantity of nodes yielded in this research is 2228408, and the overall

\begin{tabular}{|l|c|c|c|}
\hline & $\boldsymbol{q}_{\boldsymbol{n} \boldsymbol{f}}$ [watt] & $\boldsymbol{q}_{\boldsymbol{c} \mathbf{1}}$ [watt] & $\boldsymbol{q}_{\boldsymbol{c} 2}$ [watt] \\
\hline $\begin{array}{l}\text { Straight } \\
\text { Ribs }\end{array}$ & $\begin{array}{l}\text { Concentric } \\
\text { TTHEXfor } \\
\text { all Designs }\end{array}$ & 6918.2 & 9603.48 \\
\hline $\begin{array}{l}\text { Slanted } \\
\text { ribs at } \\
30^{\circ}\end{array}$ & Excluding \\
Ribs & 7828.8 & 11082.55 \\
\hline $\begin{array}{l}\text { Slanted } \\
\text { ribs at } \\
45^{\circ}\end{array}$ & 10452.87 & 8647.8 & 12673.34 \\
\hline
\end{tabular}

quantity of elements yielded is 6491481. The component varieties obtained in this meshing are tet 4 , Hex 8 , and Wed6, having a $0.5 \mathrm{~mm}$ element dimensioning.

Because graphene nanoplatelets-platinum are nonhydrophilic, they must first be dispersed in distilled water before being used in the nanofluid. Functionalizing GNPs with acid hydrolysis, which assist in the addition of functional groups such as carboxyl and hydroxyl on the GNPs interfaces, is an useful approach for it as well.

Numerical assessment of a two-pipe heat exchanger at various temperatures:

\begin{tabular}{|l|c|}
\hline \multicolumn{1}{|c|}{ Parameters } & Area $\left[\mathbf{m}^{2}\right]$ \\
\hline Lateral Surface Area external tube $=$ & 0.106640 \\
$2 \pi r_{3} l$ & \\
\hline End cross sectional of the external & 0.002201 \\
\hline
\end{tabular}

\begin{tabular}{|l|c|}
\hline tube $=\pi\left(\mathrm{r}_{3}{ }^{2}-\mathrm{r}_{2}{ }^{2}\right)$ & \\
\hline $\begin{array}{l}\text { Lateral Surface Area middletube }= \\
2 \pi r_{2} l\end{array}$ & 0.066732 \\
\hline $\begin{array}{l}\text { end cross sectional of the middle tube }= \\
\pi\left(\mathrm{r}_{2}{ }^{2}-\mathrm{r}_{1}{ }^{2}\right)\end{array}$ & 0.00119 \\
\hline $\begin{array}{l}\text { Lateral Surface of the internal } \\
\text { tube } 2 \pi r_{1}\left(l+r_{1}\right)\end{array}$ & 0.019966 \\
\hline $\begin{array}{l}\text { cross sectional of the internal tube }= \\
\pi r_{1}{ }^{2}\end{array}$ & 0.000123 \\
\hline
\end{tabular}

For all models, the temperature distribution of a Concentric TTHEX is shown.

\begin{tabular}{|l|c|c|c|c|c|c|}
\hline $\begin{array}{l}\text { Concentric } \\
\text { TTHEXfor } \\
\text { all Models }\end{array}$ & $\begin{array}{c}\text { Low } \\
\text { temperature } \\
\text { Water } \\
\text { temperature } \\
{[\text { K] }}\end{array}$ & \multicolumn{2}{|c|}{$\begin{array}{c}\text { Nano Fluid } \\
\text { temperature } \\
{[\mathbf{K}]}\end{array}$} & \multicolumn{2}{|c|}{$\begin{array}{c}\text { Normalized } \\
\text { Water } \\
\text { temperature } \\
{[\text { K] }}\end{array}$} \\
\cline { 2 - 7 } & Min. & Max. & Min & Max & Min. & Max \\
\hline $\begin{array}{l}\text { Excluded } \\
\text { Ribs }\end{array}$ & 282 & 293.71 & 322.15 & 343 & 290 & 312.92 \\
\hline $\begin{array}{l}\text { Straight } \\
\text { Ribs }\end{array}$ & 282 & 297.94 & 320.83 & 343 & 290 & 316.45 \\
\hline $\begin{array}{l}\text { Slanted ribs } \\
\text { at } 30^{\circ}\end{array}$ & 282 & 302.64 & 319.92 & 343 & 290 & 315.86 \\
\hline $\begin{array}{l}\text { Slanted ribs } \\
\text { at } 45^{\circ}\end{array}$ & 282 & 304.59 & 316.95 & 343 & 290 & 320.22 \\
\hline
\end{tabular}

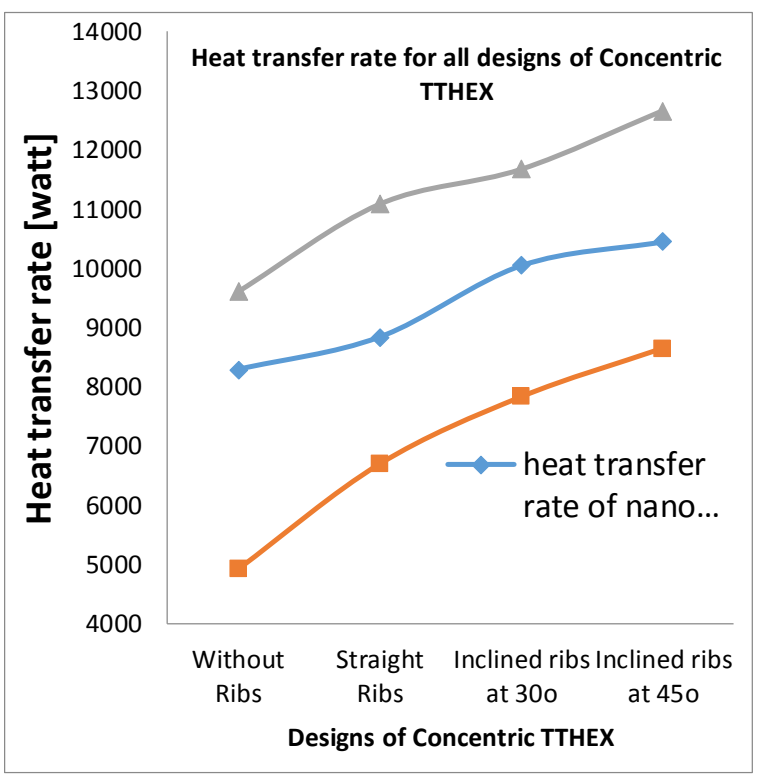

Figure 9: Heat transfer rate for all designs of Concentric TTHEX 


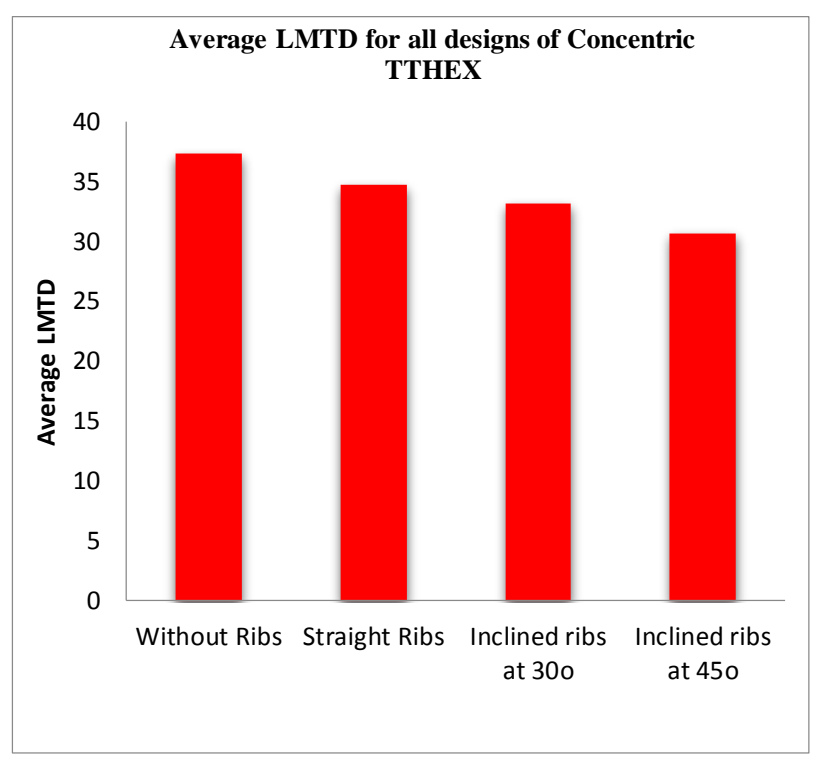

Figure 10Average LMTD for all designs of Concentric TTHEX

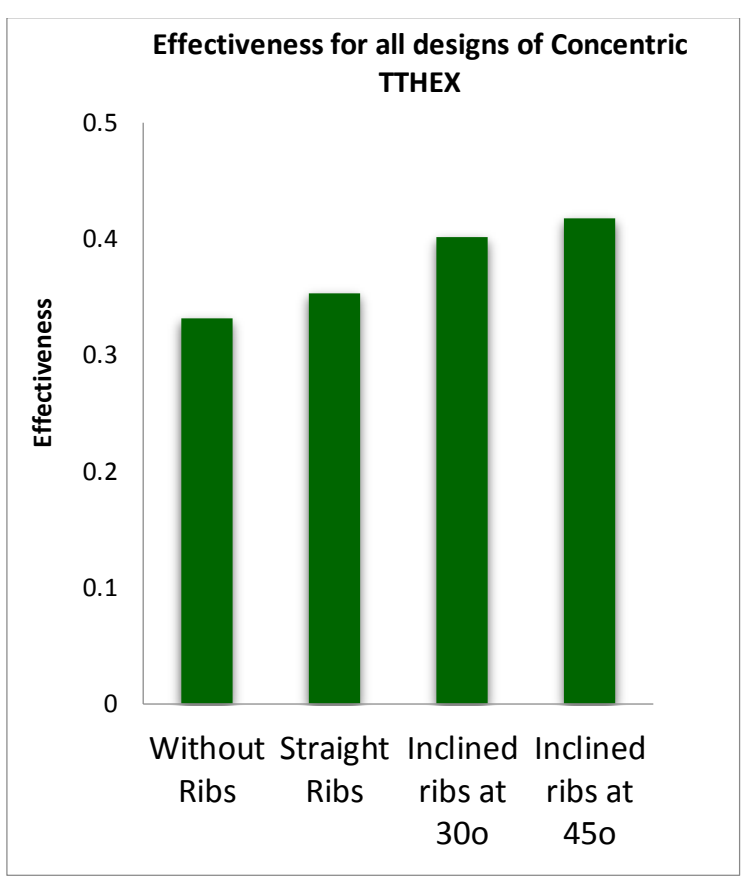

Figure 11 Effectiveness for all designs of Concentric TTHEX

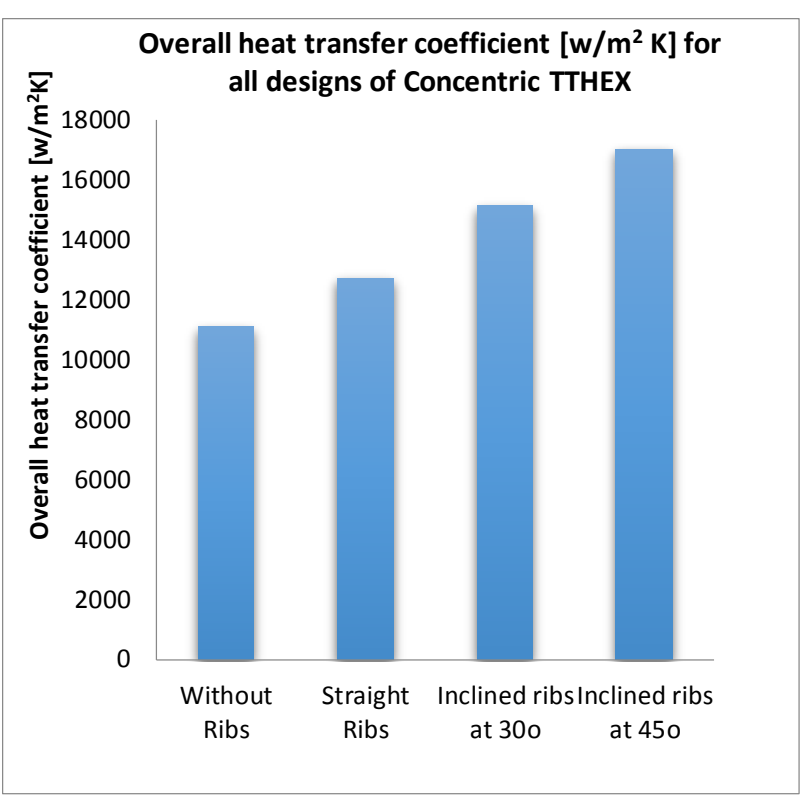

Figure 12 Overall heat transfer coefficient $[w / m 2 ~ K]$ for all designs of Concentric TTHEX

\section{CONCLUSION}

For the purpose of improving thermal efficiency, analytical and numerical fluid dynamics analyses of various styles of a concentric TTHEX were conducted in this study. For this, overall of four models have been used to check its thermal efficiency under same initial conditions. For solid walls, the momentum boundary condition with no slip is used, with the heat flux set to zero for the external side wall to achieve a heat transfer condition, whereas the internal tube walls and ribs are coupled. The external and internal tube sides' inlets are set to mass transfer inlet, while the outlets are set to press outlet. In the computational domains, fluent software is used to determine fluid circulation and heat transfer. The governing equations are iterative manner remedied using the SIMPLE algorithm and the boundary element conceptualization. Since the swirling effect on turbulence has better accuracy than the standard k-epsilon concept, the RNG k-epsilon framework is used for turbulence, and the 2nd order upwind scheme is used for momentum energy turbulence and its rate of dissipation.

\section{REFERENCE}

[1] Bahiraei, M., Mazaheri, N., \&Rizehvandi, A. (2019). Application of a hybrid nanofluid containing graphene nanoplatelet-platinum composite powder in a triple-tube heat exchanger equipped with inserted ribs. Applied Thermal Engineering, 149, 588-601.

https://doi.org/10.1016/j.applthermaleng.2018.12.07 2

[2] Said, Z., Rahman, S. M. A., El Haj Assad, M., \&Alami, A. H. (2019). Heat transfer enhancement and life cycle analysis of a Shell-and-Tube Heat Exchanger using stable $\mathrm{CuO} /$ water nanofluid. 
Sustainable Energy Technologies and Assessments, 31(December 2018), 306-317. https://doi.org/10.1016/j.seta.2018.12.020

[3] Karimi, A., Al-Rashed, A. A. A. A., Afrand, M., Mahian, O., Wongwises, S., \&Shahsavar, A. (2019). The effects of tape insert material on the flow and heat transfer in a nanofluid-based double tube heat exchanger: Two-phase mixture model. International Journal of Mechanical Sciences, 156(December 2018), 397-409. https://doi.org/10.1016/j.ijmecsci.2019.04.009

[4] Mahdi, J. M., Lohrasbi, S., Ganji, D. D., \&Nsofor, E. C. (2019). Simultaneous energy storage and recovery in the triplex-tube heat exchanger with $\mathrm{PCM}$, copper fins and $\mathrm{Al} 2 \mathrm{O} 3$ nanoparticles. Energy Conversion and Management, 180(May 2018), 949961.

https://doi.org/10.1016/j.enconman.2018.11.038

[5] Nakhchi, M. E., \&Esfahani, J. A. (2018). Cu-water nanofluid flow and heat transfer in a heat exchanger tube equipped with cross-cut twisted tape. In Powder Technology (Vol. 339). Elsevier B.V. https://doi.org/10.1016/j.powtec.2018.08.087

[6] Bahiraei, M., KianiSalmi, H., \&Safaei, M. R. (2019). Effect of employing a new biological nanofluid containing functionalized graphene nanoplatelets on thermal and hydraulic characteristics of a spiral heat exchanger. Energy Conversion and Management, 180(October 2018), 72-82.

https://doi.org/10.1016/j.enconman.2018.10.098

[7] Sheikholeslami, M., Rezaeianjouybari, B., Darzi, M., Shafee, A., Li, Z., \& Nguyen, T. K. (2019). Application of nano-refrigerant for boiling heat transfer enhancement employing an experimental study. International Journal of Heat and Mass Transfer, 141, 974-980. https://doi.org/10.1016/j.ijheatmasstransfer.2019.07. 043

[8] Sajawal, M., Rehman, T. U., Ali, H. M., Sajjad, U., Raza, A., \& Bhatti, M. S. (2019). Experimental thermal performance analysis of finned tube-phase change material based double pass solar air heater. Case Studies in Thermal Engineering, 15, 100543. https://doi.org/10.1016/j.csite.2019.100543

[9] Shafieian, A., Khiadani, M., \&Nosrati, A. (2019). Thermal performance of an evacuated tube heat pipe solar water heating system in cold season. Applied Thermal Engineering, 149(December 2018), 644657. https://doi.org/10.1016/j.applthermaleng.2018.12.07 8

[10] Elbahjaoui, R., El Qarnia, H., \&Naimi, A. (2018). Thermal performance analysis of combined solar collector with triple concentric-tube latent heat storage systems. Energy and Buildings, 168, 438456. https://doi.org/10.1016/j.enbuild.2018.02.055

[11] Jagirdar, M., \& Lee, P. S. (2018). Mathematical modeling and performance evaluation of a desiccant coated fin-tube heat exchanger. Applied Energy, 212(December 2017), 401-415. https://doi.org/10.1016/j.apenergy.2017.12.038

[12] Akyürek, E. F., Geliş, K., Şahin, B., \&Manay, E. (2018). Experimental analysis for heat transfer of nanofluid with wire coil turbulators in a concentric tube heat exchanger. Results in Physics, 9, 376-389. https://doi.org/10.1016/j.rinp.2018.02.067

[13] Mahdi, J. M., Lohrasbi, S., Ganji, D. D., \&Nsofor, E. C. (2018). Accelerated melting of PCM in energy storage systems via novel configuration of fins in the triplex-tube heat exchanger. International Journal of Heat and Mass Transfer, 124, 663-676. https://doi.org/10.1016/j.ijheatmasstransfer.2018.03. 095 